\title{
Rebellion and Return: Probing into the Marriage and Family Values of Generation X
}

\author{
Bingtian Zhang
}

\begin{abstract}
Family is a basic form of social life while marriage is a prerequisite for family formation. Marriage takes various forms in different periods in the same country; and family values vary in different historical periods and under different historical conditions. Influenced by the counterculture movement in the 1960s, Generation $X$, the offspring of the baby boomers, have inherited the rebellious and challenging spirit against the traditional American mainstream marriage and family values; meanwhile, affected by the rise of neo-conservatism and anti-feminist movement, Generation $X$ have approved of and thus returned to the traditional American marriage and family values. By interpreting the novel of Generation $X$ from literary and historical perspectives, the marriage and family values of Generation $X$ have been analyzed and elaborated.
\end{abstract}

Index Terms-Generation $\mathrm{X}$, marriage and family values, Hippies, baby boomers, Coupland.

\section{INTRODUCTION}

A group of young and middle-aged American postmodern writers, born in the 1950s and 1960s and rose in the late 1980s and early 1990s, were called "Generation X" writers. In terms of literary concern and writing style, "Generation X" writers have inherited the merits of other post-modern predecessors, making bold innovations and reflecting distinctive characteristics of the times, as concluded by W. Gan in [1]. Douglas Coupland is an important member of the "Generation X" writers as the term "Generation X" was actually derived from his representative novel Generation X created in 1991 referring to the American generation born in the years between 1965-1977, the next generation to the "baby boomers" born in the years between 1946-1964 after the Second World War.

American society in the 1960 s featured a variety of intertwined social movements whose backbone were Hippies most of whom were "baby boomers". The definition of "Generation X" has convened a similar group totaling up to 48 million Americans who constitute the young adult population and the fresh troops scattered throughout all trades and professions in the United States. According to D. Zhang and Y. Shi's summary in [2], in his masterpiece Generation X, Douglas Coupland has attempted to comprehend, examine and criticize the humanistic system, concepts of values and social consciousness of the Generation $\mathrm{X}$ from various perspectives, showing the young generation's quest for the lost meaning of life and exposing

Manuscript received November 25, 2013; revised January 27, 2014.

Bingtian Zhang is with the School of Fundamental Studies, Shanghai University of Engineering Science, Shanghai, 201620 P. R. China (e-mail: bingtianzhang@sues.edu.cn). the American postmodern survival state of distress, depression and anxiety.

Through interpreting the texts of the novel Generation X, this paper aims at probing into the marriage and family values of Generation X from literary and historical perspectives.

\section{INHERITANCE AND EVOLUTION OF THE WESTERN MARRIAGE AND FAMILY VALUES}

In human context, a family is a group of people affiliated by consanguinity, affinity, or co-residence/shared consumption [3]. Family is a basic form of social life while marriage is a prerequisite for family formation. Marriage, restricted by the social legal systems, social trends and sentiment, takes various forms in different periods in the same country; and family values, which are perceptions of how to engage in family life and attitudes of family composition, behavior of family members and the relationship between family members, vary in different historical periods and under different historical conditions. In this regard, Q. Yan concluded in [4] that marriage and family system has dual properties-social and biological. The social function of marriage and family system is mainly to meet the social needs of reproducing population and culture; the biological function is to meet the basic requirements of human biological nature. Different operation modes in the history of western marriage and family system, in fact, were the structural balancing of the dual properties reflected at different historical times.

\section{A. Ancient Greek and Roman Times}

Ancient Greece and Rome, the two sources of western civilization, shared resembling marriage and family systems with two main characteristics: Firstly, the existence of marriage and family system was to obtain population and cultural reproduction, especially the reproduction of lawful citizens. In this context, marriage was filled with responsibilities and obligations. The social property of marriage and family system was highly valued. Secondly, the father had absolute authority in the family, dominating the entire family property, his wife and children as a patriarch. The father got married simply to have children and women's rights succumbed to the authority of men.

\section{B. Medieval Europe}

Christian theocracy predominated in medieval Europe, advocating absolute asceticism and maintaining that the meaning of survival of all people on earth is to obtain recognition of God and go to heaven. Inevitably, marriage and family system had been deeply affected. Church affirmed the doctrines such as the unique and non-cancellable marital relationship, sexual restraint, etc. Therefore, the marriage and 
family system became a compromise between completely cutting off people's biological desire and meeting the social requirements of population reproduction.

\section{Europe after the Renaissance and the Industrial Revolution}

With the rapid development of social productivity, the popularity of school education and the progress of social service, the population reproduction function of marriage and family chiefly consisted in the limited liability in bearing offspring and bringing them up to adulthood while other liability was assumed by the grownup individuals themselves Consequently, the biological property of marriage and family system was accorded adequate space for development. In other words, due to the weakened liability of population reproduction, the social function of marriage and family system mainly took the form of social culture reproduction. With the rise of science and decline of religion, the biological requirements were gradually viewed as proper human requirements. On this basis, people sought to pursue the crystallization of the human biological requirements-love which was accepted as the sole basis for the establishment of a modern monogamy.

\section{America with Booming Social Movements in $1960 \mathrm{~s}$}

In the 1960s, along with the surging American social movements, a number of traditional social norms including the traditional Puritan concepts of marriage and family had been questioned and challenged. Under these circumstances, the baby boomers no longer considered it natural to get married and found a family. They maintained that there should be multiple choices about lifestyle and individuals had the freedom to pursue ways of life in line with their wishes. As a result, family, the cornerstone of society, was corroded, leading to a series of social problems. In the late 1960s, the Counterculture Movement reached its climax when living in communes, homosexuality and sexual liberation won broad support among youngsters and turned into means of confronting reality and pursuing self-actualization in combination with drugs and rock music. In a word, living in communes, homosexuality and sexual liberation of the Hippies had had a huge impact on the American social ethics and the American concepts of marriage and family, which in turn profoundly and lastingly influenced the new American generation-Generation X.

\section{GENERATION X's SUCCESSION TO THE COUNTERCUlTuRE SPIRIT OF HIPPIES AND REBELLION AgAinst the Traditional AMERICAN MARRIAGE AND FAMILY VALUES}

\section{A. Choice of Lifestyles}

The three protagonists of the novel Generation $X$ Andy, Dago and Claire came to the desert town of Palm Springs in California in pursuit of the lost true meaning of life. The three adjacent neighbors with the same ideals of life, far away from the commercial hustle and bustle of modern urban civilization, shared their life experiences through telling bedtime stories. Nonetheless, just as Andy said, "for the record, just as happened with me, Dag and Claire never fell in love, either.......and I must say, if nothing else, all of us just being friends does simplify life." (Coupland, 61) Claire's daily behaviors with Andy and Dago were very close, which however were "entirely platonic". (Coupland, 61) This pure friendship beyond romantic love apparently derived from the fathers of Generation X-Hippies. After the outbreak of the Counterculture Movement in 1960s, the mainstream middle-class family values had increasingly weakened. Hippies preferred to seek friendship in the same camp, rather than confiding in their parents. And Hippies meant to be friendly with indiscriminate and all-round love. In addition, Hippies chose to live in communes to transcend the shackles of traditional family, eliminate interpersonal barriers and promote friendship. Similarly, the collective way of life of Generation X could not gain recognition from the traditional American family values claiming that "guys just aren't friends with girls". (Coupland, 61) Andy once complained that Claire's siblings "appeared from Los Angeles to grill myself and Dag about our relationship with Claire", (Coupland, 61) and even rushed "in Claire's bungalow checking her bed sheets for strange hairs", (Coupland, 61) regardless of the invasion of privacy.

\section{B. Generation Gap between Generation $X$ and Parents}

Due to the different growing environment and life experiences, there has been a huge gap between Generation $\mathrm{X}$ and their father generation-the baby boomers, which resulted in contrasting values of life between the two generations. For instance, Andy insisted that his parents were complacent about their life. "They will battle the forces of change; they will manufacture talismans against it..... They will putter away inside the house until the future, like a horrible diseased drifter, breaks its way inside and commits an atrocity in the form of death or disease or fire or (this is what they really fear), bankruptcy. The drifter's visit will jolt them out of complacency; it will validate their anxiety." (Coupland, 144) In fact, when the Counterculture Movement sparked by the baby boomers receded gradually, the deteriorating economic conditions in the 1970s made the Hippies choose to return to sanity, survival becoming the topmost priority. Therefore, they re-approached the mainstream American culture and once again became the backbone of society. But in the eyes of Generation X, the baby boomers had already lost their questioning and challenging spirit for the middle-class mainstream culture and lifestyles sparked during the Counterculture Movement. They were also fearful of the future and any potential changes, living in the shadows of reality submissively.

\section{Views on Homosexuality}

Y. Chen has given a detailed account of the changes in the public opinions about homosexuality in [5]. Before the 1960s, homosexuality had long been regarded as a psychopathy in the United States. In the 1960s, sexual freedom and sexual liberation were important means of revolting against the mainstream culture and seeking personal freedom. With the Counterculture Movement and other social movements rising, homosexuals started fighting for their equal rights through establishing homosexual organizations and carrying out struggles. The 1970s and 1980s, thanks to the further 
development of the homosexual rights movement, witnessed American public's views on homosexuals tending to more tolerant. However, in the 1980 s, the rapid spread of AIDS reignited social prejudice, discrimination and even violence against homosexuals. Affected by the neo-conservatism in the 1980s, Generation $\mathrm{X}$ born and raised during the Counterculture Movement, though rejecting sexual freedom and sexual liberation as antidotes to the traditional culture as Hippies, had a more tolerant attitude of acquiescence towards homosexuality. In the novel, Dago's boss Mr. MacArthur, the owner of Larry's Bar, was a Yuppie, a former Hippie who had returned to the mainstream society. On one occasion, he made a joke out of lesbians. In that case, to express support for homosexuals, Dago repeated his personal tag line, "I'm a lesbian myself. I just happen to be trapped in a man's body." (Coupland, 68) Claire used to be immobilized for years in hospitals because of a long-past childhood illness. In the treating process, "she also spent the formative years of her life conversing with healing invalid souls-institutional borderline cases, the fringed, and the bent." (Coupland, 36) She claimed, "to this day, I prefer talking with incomplete people; they're more complete." (Coupland, 36)

\section{GENERATION X's RETURN TO THE TRADITIONAL AMERICAN MARRIAGE AND FAMILY VALUES}

\section{A. Social Background of the Return}

Neo-conservatism was a conservative force originating in the 1960s, developing in the 1970s, becoming active in the 1980s and 1990s, and exerting the greatest influence at the turn of the century. Between the late 1960s and early 1970s, on account of a series of increasingly serious social problems directly or indirectly arising out of liberal ideas and liberal policies, such as the proliferation of pornography, the spread of drug abuse, uncontrolled sexual freedom, rise in juvenile delinquency and the expanding social welfare groups, the neo-conservative emphases on moral values, the spirit of individual responsibility and the traditional way of life appealed greatly to ordinary Americans. As E. Wang put it in [6], neo-conservatives were devout believers in laisser-faire capitalism, inheriting and defending the spirit of capitalism from a moral dimension. What's more, neo-conservatives were not only concerned about the problem of securing personal freedom, but also interested in social and moral issues, adding some moral and spiritual elements stressed by traditional values. Under the influence of the neo-conservatism, compared with the baby boomers, Generation $\mathrm{X}$ have attached greater importance to and been supporters of the conservative traditional political and family values.

In order to promote women's liberation and seek equal rights, American feminists launched a feminist movement in the 1960s. Under the influence of the feminist movement, women had become more economically self-reliant, resulting in more autonomy and independence in the marriage. However, with the improvement of the status of American women in society and the family, a series of social problems followed, such as a sharp rise in the divorce rate, delayed age at first marriage and child-bearing, improved non-marital birth rates, an increase in single-parent families, etc. Consequently, the 1970s saw the booming of the "anti-feminist movement" which was a rebound to the feminist movement, homosexual rights movement and the proliferation of abortion and pornography, calling on the restoration of traditional American values. In the 1980s, the anti-feminist movement became a powerful force in American politics [7]. Influenced by the movement, Generation X were so upset about social problems such as incomplete families and moral degeneration that they chose to support and thus return to the conservative traditional American marriage and family values.

\section{B. Manifestations of Generation X's Return to the Traditional American Marriage and Family Values}

\section{1) A mockery of the high divorce rate in American society}

A large proportion of Generation $X$ when growing up underwent blind divorce and remarriage of their parents as well as family reorganization. In the novel of Generation $X$, Claire's family was a typical example. Her brothers and sisters were called in the novel "incalculably numerous and noisy siblings, half-siblings, step-siblings chatter incessantly out in the sun by the pools, like parakeets in an aviary while a sullen, hungry tomcat prowls outside the cage's mesh." (Coupland, 33) Claire's father's fourth wife was described as a "glistening and be-gemmed business cronies......blond and young and bored, glowering at the Baxter spawn like a mother mink in a mink farm, just waiting for a jet to strafe the facility, affording her an excuse to feign terror and eat her young." (Coupland, 34) Their marriage seemed like an interest-based business transaction. In addition, as a result of family restructuring, relationships among Claire's family members were complicated and estranged, lacking traditional family values and the simplicity and intimacy among traditional nuclear family members. For instance, Claire's family once spent a weekend in Palm Springs when Mr. Baxter had a heart attack causing a chaotic scene. But "you could tell the Baxters amid the chaos by their lack of concern with the excitement, pointing languidly toward the hubbub when the two paramedics and their trolley (a familiar sight in Palm Springs) arrived." (Coupland, 38) Prior to the heart attack, Mr. Baxter stole ordinary tableware from the resort bar, hidden in a pocket. In the rescue process, the tableware unexpectedly slipped and broke, exposing the truth and triggering other guests' ridicule. Allan, Barter's son, went so far as to satirize his father in the presence of strangers, "How could you embarrass us like this? ...... It's obviously only plate. Haven't we trained you properly?" (Coupland, 38)

As a member of Generation X, Claire opted to examine, criticize and stay away from this deformed family in the eyes of bystanders. Andy's impression on her blended family was that they "talk about pretense" (Coupland, 34) and "the morbid snippets of chitchat that were being prattled around the table by the hordes of sleek and glamorous young Baxters", (Coupland, 34) while Claire "sat looking profoundly unamused by her family's spirited, italicized conversations." (Coupland, 34) Later, Claire turned to leave for the bar counter where Andy was working, just making shrugging and a contemptuous gesture. Soon afterwards, Claire chatted frankly with Andy, accurately pointing out the 
status quo of marriage and family in America, "I really think that when God puts together families, he sticks his finger into the white pages and selects a group of people at random and then says to them all, 'Hey! You're going to spend the next seventy years together, even though you have nothing in common and don't even like each other." (Coupland, 36) Eventually, at Andy's proposal, Claire chose to escape from her eccentric family to pursue the lost true meaning of life together with congenial Andy and Dago. Obviously, Generation $\mathrm{X}$ had no alternative but to abandon their past life, placing themselves in the margins of society willingly and expressing their helplessness to the increasingly collapsing family and marital relations by self-isolation.

\section{2) A yearning for harmonious family relations}

In the second part of the novel, Andy, Dago, Claire, Elvissa and Tobias, the five Generation X members, once got together to discuss what had been the most unforgettable memories on the earth, "small moment from your life that proves you're really alive." (Coupland, 91) Surprisingly, although there was a huge generation gap between Generation $\mathrm{X}$ and the baby boomers due to the differences in the growing-up environment and life experiences, Andy, Dago and Tobias's recollections centered on their family life without exception.

Take Andy as an example. In the novel, he recalled three fragments of his family life. The first scenario was his eating breakfast with other eight family members. He said "I knew even then that this was the only such morning our family would ever be given - a morning where we would all be normal and kind to each other and know that we liked each other without any strings attached-and that soon enough (and we did) we would all become batty and distant the way families invariably do as they get along in years." (Coupland, 95) "I was feeling homesick for the event while it was happening...... and it's those little pinpricks and the smell of bacon that I'm going to be taking away with me; that will be my memory of earth." (Coupland, 95) The second scene was that Andy recalled his whole family went to have a family portrait taken 15 years ago, which, as Andy mentioned, "remains as possibly the most unhip day of my life", (Coupland, 133) and in the group portrait, "we're beaming earnestly to the right, off toward what seems to be the future". (Coupland, 133) When the family portrait just arrived, Andy's father solemnly placed it in the most conspicuous place on the fireplace. However, an hour later, his father had to take down the photo and removed it to a spot no one would care about at the children's dissuasion, for "everyone in the family finally decided to stop trying to live up to that bloody photo and the shimmering but untrue promise it made to us......the year we went the way families just do, the year everyone finally decided to be themselves and to hell with it." (Coupland, 134) On the third scene, Andy hurried back to Portland where his parents were living to attend family gatherings at Christmas as in previous years. Although, in the eyes of Generation X, Christmas was no more than "righteously abandoned meals, and the traditional family psychodramas", (Coupland, 136) Andy still bought hundreds of candles on the Christmas day cover the dull monotony of daily life. The moment candles were lit, "All of us are instantaneously disembodied from the vulgarities of gravity; we enter a realm in which all bodies can perform acrobatics like an astronaut in orbit, cheered on by febrile, licking shadows." (Coupland, 146) And, "this light is also making the eyes of my family burn, if only momentarily, with the possibilities of existence in our time." (Coupland, 146) It can be seen that irrespective of the insurmountable ideological gap between Generation X and their parents, Generation X have expressed their remembrance and yearning for harmonious family relationships through telling about the most unforgettable life fragments, which undoubtedly was praise of and return to the American concepts of traditional family life.

\section{3) A more conservative attitude towards sex}

The Counterculture Movement of the 1960s has made a far-reaching impact on the contemporary concepts of marriage and family in the United States, exemplified by the soaring divorce rate, disintegrating family relations, decaying social ethics, an AIDS epidemic and other social problems brought about by the sexual revolution and sexual liberation initiated by the Hippies. Hippies opposed Protestant ethics about gender relations, advocating sexual revolution and sexual liberation. In the 1970 s when the Counterculture Movement had receded, most Hippies returned to the mainstream American society, with more and more Americans accusing Hippies of the immoral sexual behaviors and the sexual liberation. A decade later, with the rise of neo-conservatism, Generation X, born and raised during the Counterculture Movement, had a relatively more conservative attitude towards sexual life and recognized the traditional marriage and family life based on love, just like their fathers who had returned to the mainstream culture, although showing a more tolerant attitude towards homosexuals.

Dago's attitude towards sex may be taken as an example. Fed up with the middle-class nine-to-five working pattern, Dago quitted his job as a salesman at an advertising agency to "try and shake the taint that marketing had given me". (Coupland, 27) When talking of sexual life, Dago completely abandoned the conceptions of sexual revolution and sexual liberation that had been cherished by Hippies. Dago claimed that "I became nonsexual and my body felt inside-out - covered with ice and carbon and plywood like the abandoned mini-malls, flour mills, and oil refineries of Tonawanda and Niagara Falls. Sexual signals became omnipresent and remained repulsive. Accidental eye contact with 7-Eleven grocery clerks became charged with vile meaning....... Starved for affection, terrified of abandonment, I began to wonder if sex was really just an excuse to look deeply into another human being's eyes." (Coupland, 30)

\section{CONCLUSION}

Generation itself is a national subculture, reflecting the chief values of a country's specific historical periods. The subculture of generation is of great importance for understanding the evolving process of cultural development, embodying the essence of a country's cultural changes. Generation $\mathrm{X}$ has constituted a young adult population of the 
United States currently spread over various trades and industries through the country. As the next generation of baby boomers, influenced by the Counterculture Movement, Generation $\mathrm{X}$ have partially inherited the rebellious and questioning spirit of Hippies against the traditional American conceptions of marriage and family. Meanwhile, affected by the rise of the neo-conservatism and the anti-feminist movement, Generation X eventually chose to recognize and return to the traditional American marriage and family values. As for the future of cultural changes in the United States, with Generation X gradually mastering the power and status in American society, the impact of this generation's value orientation on American culture will become more widespread and deeper.

\section{REFERENCES}

[1] W. Gan, "The emerging 'generation X' writers in american literature: an interview with professor Yang Renjing," Foreign Literature Studies no. 1, pp. 1-7, Feb. 2007.

[2] D. Zhang and Y. Shi, "In pursuit of the lost meaning-A study of the theme of pursuit in douglas coupland's Generation X," Theory Horizon, no. 3, pp. 140-142, Aug. 2013.
[3] Family. (Jan. 2014). Wikipedia. [Online]. Available: http://en.wikipedia.org/wiki/Family

[4] Q. Yan, "A discourse upon the duality of the western marriage and family system," Population Journal, no. 3, pp. 35-38, June 2002.

[5] Y. Chen, "Contemporary dynamics in America'S families and Marriage patterns and the influence," World Ethno-National Studies, no. 2, pp. 60-70, April 2006.

[6] E. Wang, "The rise of contemporary American new conservatism," International Review, no. 2, pp. 51-58, March 2006.

[7] J. Zhou, "On the American marriage and family changes in the 1970s," Journal of Guizhou Educational College, no. 4, pp. 88-92, Dec. 1998.

[8] D. Coupland, Generation X-Tales for an Accelerated Culture, New York: St. Martin's Press, 1991.

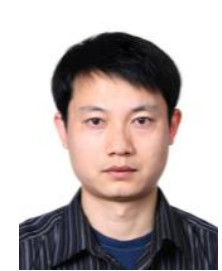

Bingtian Zhang was born in Shenyang, Liaoning province, P. R. China on December 22, 1978. He studied English language and literature in Shandong University, Jinan, Shandong Province, P. R. China from 1997 to 2001 and obtained his bachelor's degree in July, 2001. After that, he pursued his study in foreign linguistics and applied linguistics in Dalian Maritime University, Dalian, Liaoning province, P. R. China and obtained his master's degree in April, 2004 Now, he is an English teacher of the School of Fundamental Studies, Shanghai University of Engineering Science, Shanghai, P. R. China. His research interests include American history and literature 